\title{
THE PHONETICS AND PHONOLOGY OF INTONATIONAL PHRASING IN ROMANCE*
}

\author{
SÓNIA FROTA ${ }^{1}$, MARIAPAOLA D'IMPERIO ${ }^{2}$, \\ GORKA ELORDIETA ${ }^{3}$, PILAR PRIETO ${ }^{4} \&$ MARINA VIGÁRIO $^{5}$ \\ ${ }^{1}$ Universidade de Lisboa, ${ }^{2}$ Laboratoire Parole et Language - CNRS, \\ ${ }^{3}$ Euskal Herriko Unibertsitatea, ${ }^{4}$ ICREA \& Universitat Autònoma de \\ Barcelona, ${ }^{5}$ Universidade do Minho
}

\begin{abstract}
This paper examines the phonetics and phonology of intonational boundaries in five Romance languages/varieties. A typology of the boundary cues used is given, as well as their relative frequency. The phonology of the tonal boundary gesture is described by means of the inventory of nuclear accents used plus their possible combinations with the two dominant end contours: continuation rise (H) and sustained pitch $(! \mathrm{H})$. A detailed analysis of the phonetics of the $\mathrm{H}$ boundary tone, which is the main boundary cue observed across these languages, is provided. This involved assessing the impact on $\mathrm{H}$ scaling of nuclear accent choice, phrase length and first peak height. Overall, it is shown that the variation found consistently groups these languages in two sets: the Catalan-Spanish group and the Italian-European Portuguese group.
\end{abstract}

\section{Introduction}

Intonational phrasing in Romance has been the topic of recent research conducted within the Romance languages intonational phrasing project (Elordieta, Frota, Prieto \& Vigário 2003; Elordieta, Frota \& Vigário 2005; D’Imperio, Elordieta, Frota, Prieto \& Vigário 2005; Prieto 2005, 2007; Frota \& Vigário in press). The three main goals of this project are to establish the patterns of placement of intonational boundaries, to determine the influence of syntactic and prosodic factors on boundary placement, and to describe the phonetics and phonology of intonational boundaries. To attain these goals intonational phrasing has been studied on a corpus of laboratory speech which

\footnotetext{
* This research was funded by the Onset-Centro de Estudos da Linguagem (Onset-CEL) da Universidade de Lisboa (as part of the SILC Project), the Centro de Estudos Humanísticos da Universidade do Minho (CEHUM), and the following research grants: 9/UPV00033.130$13888 / 2001$ from the University of the Basque Country, 2002XT-00032 and 2001SGR 00150 from the Generalitat de Catalunya and HUM2006-01758/FILO from the Ministry of Science and Technology of Spain, and ACI 0220244 from the French Ministry of Research. We are grateful to the audience of the II PaPI Conference held at the Universitat Autònoma de Barcelona, especially to Bob Ladd and José Ignacio Hualde, and to two anonymous reviewers.
} 
was designed to be comparable across languages - the Romance Languages Database (RLD). The present paper emerges from this research project and is intended to address the third goal, in other words, to determine how intonational boundaries are realized in Central Catalan, in two varieties of European Portuguese (Standard and Northern EP), in Neapolitan Italian, and in Central Peninsular Spanish.

Our approach to intonation is couched within the autosegmental metrical theory (see Pierrehumbert 1980; Beckman \& Pierrehumbert 1986; Ladd 1996, among the landmarks in the development of this theoretical model). For all the languages under observation, the utterances were prosodically annotated using language-specific versions of a ToBI-like transcription (see Price, Ostendorf, Shattuck-Hufnagel \& Fong 1991; Beckman \& Ayers 1994), which took into account the work based on the autosegmental metrical model as applied respectively to each language (e.g. for Catalan, Prieto 1995; Estebas-Vilaplana 2000; Prieto, D’Imperio, Elordieta, Frota \& Vigário 2006; for European Portuguese, Vigário 1998; Grønnum \& Viana 1999; Frota 2000, 2002a, 2002b; Vigário \& Frota 2003; for Italian, D’Imperio, 2000, 2001, 2002; and for Spanish, Prieto, van Santen \& Hirschberg 1995; Prieto, Shih \& Nibert 1996; Prieto 1998; Sosa 1999; Nibert 2000; Beckman, Díaz-Campos, McGory \& Morgan 2002; Face 2002; Hualde 2002; and McGory \& Díaz-Campos 2002, among others). Thus the account of the phonetics and phonology of intonational phrasing we provide is necessarily informed and constrained by the tenets of the approach we have adopted. Using the same framework for describing intonation makes cross-language comparisons possible, and work on other languages has shown that languages may differ not only in the phonology (i.e. the inventory of tones and their permitted combinations) but also in the phonetics (i.e. the realization of tones) of intonational boundaries. For example, phonological differences between German and English question intonation are described in Ladd (1996), namely, the use of $\mathrm{H}^{*} \mathrm{LH} \%$ and $\mathrm{L}^{*} \mathrm{H}$ LH\%, respectively, and phonetic differences between German and British English in the way they exploit the phonetic space of $\mathrm{H} \%$ are reported in Chen (2003).

This paper is organised as follows. Section 2 reviews the main findings of previous research within the Romance languages intonational phrasing project and describes the RLD. Section 3 provides a typology of the boundary cues used in each language, as well as their relative frequency. In Section 4, we describe the phonological choices that characterize each language, that is, the inventory of nuclear accents used and the shape of nuclear contours observed. Section 5 deals with the phonetics of the dominant boundary cue used by all the languages under study: the $\mathrm{H}$ boundary tone. The impact of different factors on the realization of the $\mathrm{H}$ boundary tone, such as the type of nuclear accent or the length of the phrase, is examined. The paper concludes with an assessment of the similarities and differences that characterize intonational boundaries across Romance languages. 


\section{Background}

\subsection{Previous work comparing intonational phrasing in Romance}

Previous comparative work on intonational phrasing in Romance languages has focused on the role of syntactic and prosodic factors on the placement of intonational boundaries in broad focus declarative sentences containing a subject, verb and object (i.e. SVO). The import of syntactic branching (i.e. constituency), prosodic branching (i.e. number of prosodic words), and length (i.e. number of syllables) was examined in a systematic way by approaching intonational phrasing from an empirical perspective.

The collective results of these various studies demonstrate that the five Romance languages/varieties differ in their phrasing patterns. In Catalan, for example, the most common phrasing is (S)(VO) across all conditions observed (Prieto 2005; D'Imperio et al. 2005). However, Catalan is the only one of these languages where the $(\mathrm{SV})(\mathrm{O})$ phrasing pattern was also found. This phrasing obtains due to a strong tendency to balance the length of the prosodic constituents in terms of number of syllables and also number of stresses and/or prosodic words. An effect of branchingness was also found in Catalan, but the relevant factor is prosodic and not syntactic (Prieto 2005; D'Imperio et al. 2005). Standard European Portuguese (SEP) is the only language in the group with a prevalence of the (SVO) phrasing pattern. The alternative (S)(VO) pattern, also found in the data, is triggered by phrase length, not prosodic or syntactic branching. By contrast, Northern European Portuguese (NEP) shows a higher frequency of (S)(VO) phrasing than SEP, with prosodic branchingness being more important than constituent length (Elordieta et al. 2005; D'Imperio et al. 2005; Frota \& Vigário in press). The phrasing patterns shown by Italian are similar to NEP: both (SVO) and (S)(VO) are found, and the main factor triggering (S)(VO) is prosodic branchingness (D'Imperio et al. 2005). In Spanish, like in Catalan, the most common phrasing is (S)(VO) across all conditions. However, differently from the other languages, syntactic branching seems to be a major factor in phrasing decisions in Spanish (Elordieta et al. 2003; Elordieta et al. 2005; D'Imperio et al. 2005).

In all this previous work, intonational boundaries were identified and marked, but no analysis of the type and frequency of boundary cues was made. This is the object of the present paper.

\subsection{The RLD}

The Romance Languages Database contains a set of comparable SVO sentences designed with all the combinations of two constituent length conditions ('short', meaning three syllables, and 'long', meaning five syllables) and the three syntactic branching conditions (non-branching, branching and double branching $\mathrm{S}$ and $\mathrm{O}$ ). In a subset of these materials, the syntactic branching condition is substituted with a prosodic branching condition, namely a phrase with two prosodic words that are syntactically non-branching (for a full description of the RLD, see D'Imperio et al. 2005). The speech materials were read three times each in random order (with distractor sentences in 
between) by two speakers of each of the five languages/varieties under study. Examples of the speech materials are given in (1):

(1) Non-branching Subject and branching Object (Long-Short-Long)

Cat: La boliviana mirava la melmelada meravellosa.

"The Bolivian woman looked at the wonderful jam."

EP: A boliviana gravava uma melodia maravilhosa.

"The Bolivian woman recorded a wonderful song."

It: La boliviana mirava la serenata meravigliosa.

"The Bolivian woman observed the wonderful serenade."

Sp: La boliviana miraba la mermelada maravillosa.

"The Bolivian woman looked at the wonderful jam."

For the present paper, since we were exclusively interested in the phonetics and phonology of intonational phrasing, we selected only those utterances in the RLD that had been previously classified as containing a clear phrasing boundary. In other words, we analysed a subset of this database. As we were interested in the nature of the cues used to signal phrasing, we decided to consider only the uncontroversial cases of intonational phrasing, that is, those cases that were perceived by two judges (one author and one external judge) as unarguably containing a clear phrasing boundary. All cases judged unclear by one or both judges were excluded from the analysis. The results reported below are thus based on a total of 998 utterances: 239 for Catalan, 267 for EP (117 for SEP and 150 for NEP), 233 for Italian, and 259 for Spanish. Although only two speakers from each language/variety were analysed, two factors make us feel justified in claiming that we are indeed describing intonational properties of the languages and varieties under observation. First, only cases of clear phrasing were analysed. Second, the same speakers had been recorded together with other speakers for the study of different aspects of intonation and did not show deviant or atypical patterns (see Frota 2000 for Standard EP; Vigário \& Frota 2003 for NEP; and D’Imperio 2000 for Italian).

\section{Typology of boundary cues}

All the phrasing boundaries examined show one or more of the following boundary cues: (i) the preboundary stretch is realized as a rise from/on the last stressed syllable into the boundary syllable, that is, a 'continuation rise'; (ii) the preboundary stretch is realized as a rise on the last stressed syllable followed by a high plateau up to the boundary, that is, 'sustained pitch'; (iii) the boundary is signalled by a High tone; (iv) the boundary is signalled by a Low tone; (v) there is 'pitch reset' after the boundary, at the beginning of the second phrase; (vi) the F0 drops to the speaker's base level at the boundary; (vii) there is preboundary lengthening; and (viii) a pause (defined as a stretch of silence) is present at the phrasing boundary. The data were classified as containing one or more of these cues. Of this set of cues, pitch reset and 
preboundary lengthening turned out to be extremely hard to capture in a systematic and comparable way across languages, as will be explained below.

First, pitch reset was found to be either full or partial, and measuring it in a comparable fashion across languages was problematic. For European Portuguese, the peak line delineated by two (or more) preboundary peaks was used as a reference line to place the first peak of the second phrase, and peaks above the line were classified as cases of reset. This criterion matched well with the perception of pitch reset. By contrast, for Italian, a purely perceptual decision was made. For Spanish and Catalan, ratios of 0.90 or higher between the first peaks of the first and second phrases were considered cases of reset. Again, the criterion seemed to match with the auditory impression of pitch reset. Establishing the presence of preboundary lengthening in a comparable way across these languages was even harder. The database was not designed to measure lengthening, and only by chance could we avail ourselves of the same sentence uttered with and without a phrase boundary by the same speaker, the ideal case to examine lengthening effects. The few cases where such pairs were found were measured (specifically, the duration of the last stressed syllable and the preboundary syllable) and the result of the presence or absence of lengthening was extended to the utterances that were perceptually similar (with regard to the impression of lengthening) to those that were actually measured ${ }^{1}$.

\begin{tabular}{lcccccccc}
\hline & $\begin{array}{c}\text { Cont. } \\
\text { Rise }\end{array}$ & $\begin{array}{c}\text { Sustained } \\
\text { Pitch }\end{array}$ & \multicolumn{2}{c}{$\begin{array}{c}\text { Boundary } \\
\text { Tone }\end{array}$} & $\begin{array}{c}\text { Pitch } \\
\text { Reset }\end{array}$ & $\begin{array}{c}\text { Drop } \\
\text { BL }\end{array}$ & $\begin{array}{c}\text { PB } \\
\text { Length. }\end{array}$ & Pause \\
& & \multicolumn{2}{c}{ H } & L & & & & \\
\hline Cat & 100.0 & 0.0 & 100.0 & 0.0 & 28.0 & 0.0 & 100.0 & 10.5 \\
Sp & 88.4 & 11.2 & 99.3 & 0.7 & 76.0 & 0.7 & 40.2 & 28.2 \\
SEP & 95.0 & 0.0 & 95.0 & 4.0 & 25.0 & 4.0 & 15.0 & 5.0 \\
NEP & 89.0 & 8.0 & 97.0 & 3.0 & 21.0 & 1.0 & 72.0 & 17.0 \\
It & 54.5 & 45.5 & 98.7 & 1.3 & 98.0 & 0.0 & 100.0 & 16.7 \\
\hline
\end{tabular}

Table 1: Frequency of boundary cues per language.

(2) a.

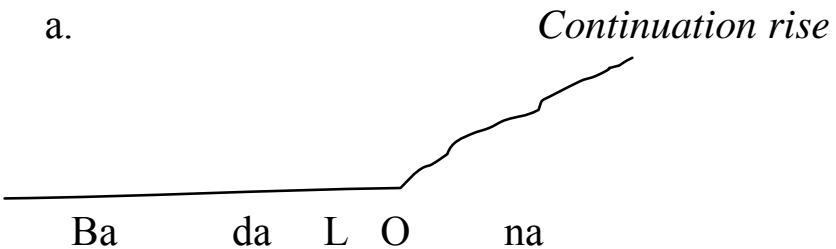

b.

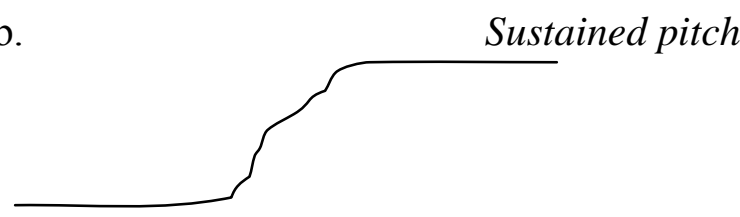

Ba da L O na "Badalona"

\footnotetext{
${ }^{1}$ In future work we plan to address the issues of pitch reset and preboundary lengthening by means of specifically designed experiments that can produce comparable data and the application of identical criteria for all languages.
} 
Table 1 shows the frequency of the different boundary cues in the languages studied. It is clear that prosodic breaks in Romance are predominantly marked by a High boundary tone. The preboundary stretch is predominantly realized as a continuation rise except in Italian, where sustained pitch is just as frequent. In all cases, the boundary is marked by a $\mathrm{H}$ tone. The two boundary configurations, sustained pitch and continuation rise, are phonetically distinct in those languages that show both types of contours, namely, Italian, Spanish, and NEP. The configurations in (2) illustrate the general patterns found in the Italian data. Figures 1 and 2 show typical contours produced with a prosodic break after the subject noun phrase in NEP and Spanish, respectively. In both figures the top panel shows a continuation rise after the subject, and the bottom shows sustained pitch.
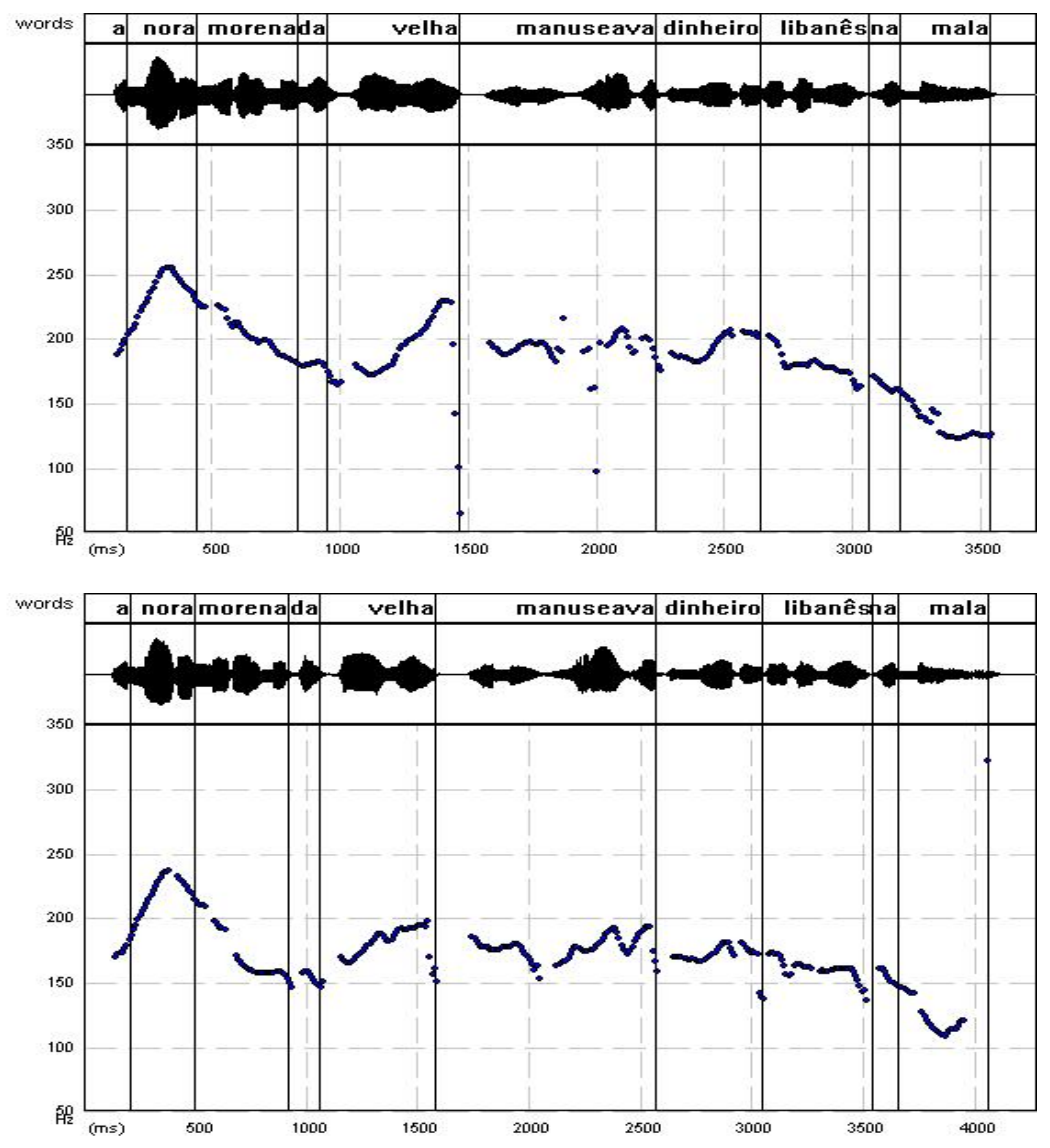

Figure 1: Waveform and F0 contour of the NEP utterance (A nora morena da velha) (manuseava dinheiro libanês na mala) "The dark-haired daughter-in-law of the old woman was holding Lebanese money in her handbag”, speaker MI.

As shown in Table 1, Low boundary tones occur in all the languages except Catalan, but are rare. The F0 drop to the speaker's base level is also 
rare. Pauses, although present in all languages, are not a frequent cue either ${ }^{2}$. As to pitch reset and preboundary lengthening, these cues appear in all the languages but are very frequent in only some of them.

Due to the dominant use of the $\mathrm{H}$ boundary tone across languages and its contribution to both a continuation rise and a sustained pitch boundary configuration, this paper will focus on the phonology and phonetics of the whole tonal gesture that signals phrasing boundaries in Romance.
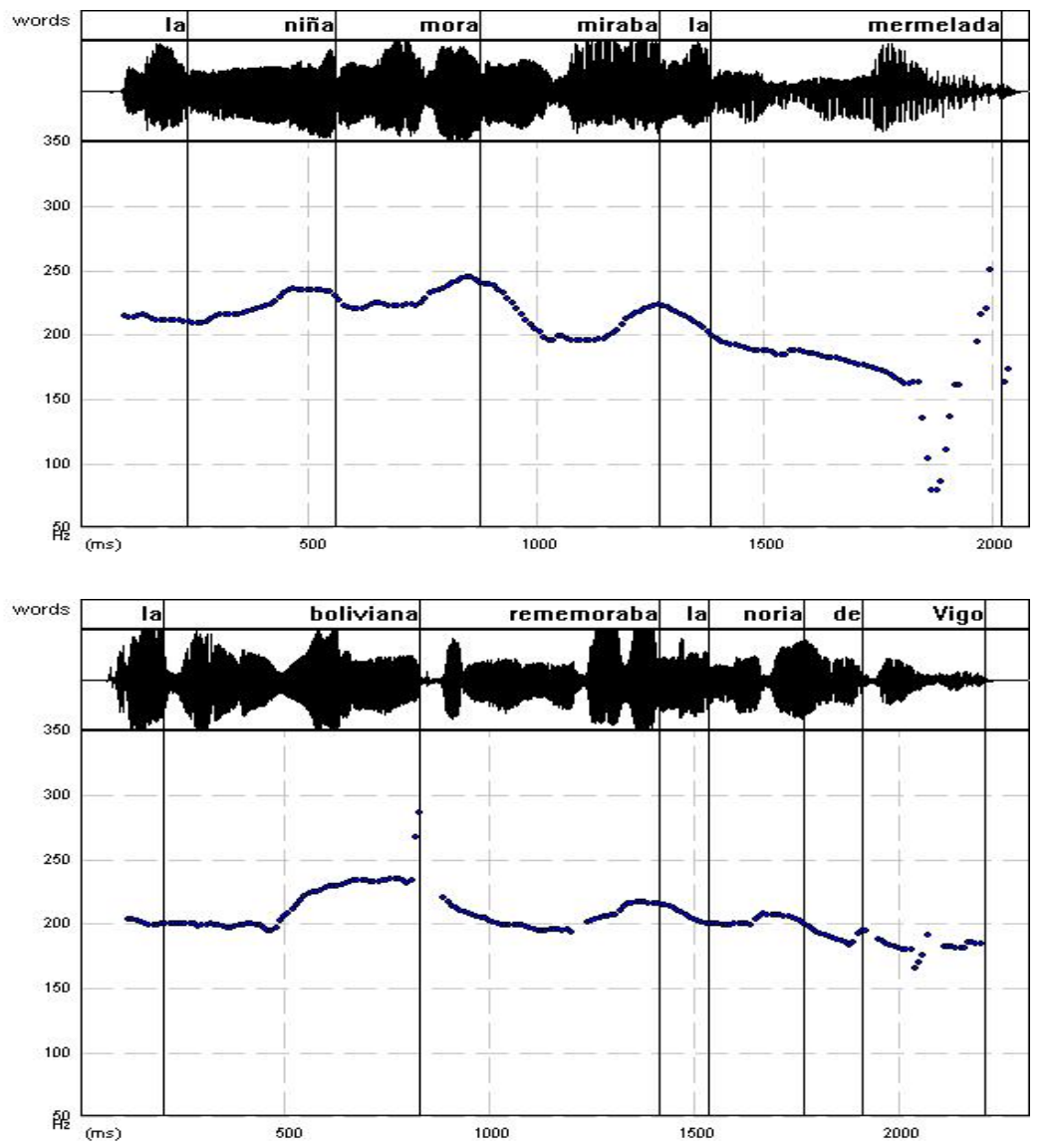

Figure 2: Waveform and F0 contour of two Spanish utterances. Top panel (La niña mora) (miraba la mermelada) "The Moorish girl looked at the jam”, speaker MR. Bottom panel: (La boliviana) (rememoraba la noria de Vigo) "The Bolivian girl remembered the ferris wheel in Vigo”, speaker LM.

\section{Phonological choices}

This section is devoted to the phonology of the continuation rise and sustained pitch tonal gestures. In Section 4.1 we describe the nuclear accents found in each language, that is, the pitch accent preceding the boundary tone. In Section 4.2 we examine the shape of the nuclear contours as a whole.

\footnotetext{
${ }^{2}$ In our data speech rate was not controlled, as speakers were simply asked to produce the utterance in a natural way at a normal speech rate. It may thus be the case that speech rate differences are responsible for differences in pause occurrence.
} 


\subsection{Nuclear accents}

Across the languages, four different nuclear accents were found before the phrasing boundary. The shapes of the tonal trajectory within the stressed syllable are schematised in (3). We describe tune-text alignment of these shapes in (4).
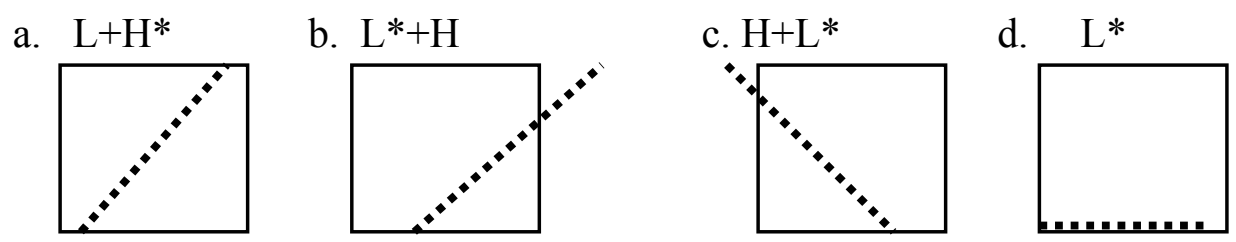

(4) Alignment description:

a. $\mathrm{L}+\mathrm{H}^{*}$ : High target attained within the stressed syllable (at the end of the vowel).

b. $\mathrm{L}^{*}+\mathrm{H}$ : Low target in the stressed $\mathrm{V}$ and high target in the poststressed syllable.

c. H+L*: Low target in the stressed $\mathrm{V}$ preceded by a high target.

d. L*: The stressed vowel remains low throughout.

The descriptions in (3) and (4) were instrumental in the identification of nuclear accents across languages, so that we could systematically apply the same category label to similar objects cross-linguistically. In addition, it is important to note that all these accents had independently been described in previous work as part of the tonal inventory of the languages described (e.g. Prieto 1995 for Catalan; Frota 1997, 2002a; Vigário 1998; Vigário \& Frota 2003 for EP; D'Imperio 2000, 2002 for Italian; Beckman et al. 2002; Face 2002; Hualde 2002; McGory \& Díaz-Campos 2002; Sosa 1999, among others for Spanish) ${ }^{3}$.

The distribution of the different nuclear accent types across languages is given in Table 2. The five languages/varieties clearly form two groups: (i) those only with rising accents or where rising accents are the overwhelming choice, that is, Spanish and Catalan; and (ii) those with both rising and falling accents, that is, SEP, NEP and Italian. Within the latter group, a further distinction can be made: SEP is different from both NEP and Italian in not showing the accents $\mathrm{L}+\mathrm{H}^{*}$ and $\mathrm{L}^{*}$. This does not come as a surprise as $\mathrm{L}^{*}$ has been reported to be the most frequent nuclear accent in NEP declarative accents, whereas SEP has $\mathrm{H}+\mathrm{L}^{*}$ as the declarative nucleus (Vigário \& Frota 2003), and $\mathrm{L}+\mathrm{H}^{*}$ has never been reported as a possible accent in SEP to our knowledge.

\footnotetext{
${ }^{3}$ The rare cases of falling accents found in Catalan require a further comment. These cases may fall in either the $\mathrm{H}+\mathrm{L}^{*}$ or $\mathrm{L}^{*}$ category, as they are ambiguous between the two and may well be variants of the same accent. We have classified them as $\mathrm{H}+\mathrm{L}^{*}$ for the sake of simplicity.
} 


\begin{tabular}{|c|c|c|c|c|c|}
\hline & & $\mathrm{L}+\mathrm{H}^{*}$ & $\mathrm{~L} *+\mathrm{H}$ & $\mathrm{H}+\mathrm{L}^{*}$ & $\mathrm{~L}^{*}$ \\
\hline \multirow[t]{2}{*}{ Cat } & NM & 97 & 0 & 3 & 0 \\
\hline & PG & 100 & 0 & 0 & 0 \\
\hline \multirow[t]{2}{*}{$\mathrm{Sp}$} & LM & 27 & 73 & 0 & 0 \\
\hline & MR & 5 & 95 & 0 & 0 \\
\hline \multirow[t]{2}{*}{ SEP } & $\mathrm{AG}$ & 0 & 57 & 43 & 0 \\
\hline & $\mathrm{MC}$ & 0 & 11 & 89 & 0 \\
\hline \multirow[t]{2}{*}{ NEP } & MI & 19 & 57 & 7 & 17 \\
\hline & MS & 0 & 0 & 14 & 86 \\
\hline \multirow[t]{2}{*}{ It } & LC & 47 & 0 & 0 & 53 \\
\hline & LD & 41 & 0 & 59 & 0 \\
\hline
\end{tabular}

Table 2: Distribution of nuclear pitch accent types (\% relative to total of utterances by speaker) per language and speaker.

\subsection{Nuclear contours}

We will now consider the contribution of the nuclear accents to the two predominant types of nuclear contours we have found: continuation rise and sustained pitch. The four different accents participate in the continuation rise and sustained pitch boundary configurations as described in Table 3. Not surprisingly, falling/low accents only appear with continuation rises. Rising accents, on the other hand, show two interesting patterns which again divide Romance languages into the same two groupings: (i) Catalan and Spanish; and (ii) SEP, NEP and Italian. In the latter group there is a strong connection between $\mathrm{L}^{+} \mathrm{H}^{*}$ and sustained pitch, and $\mathrm{L}^{*}+\mathrm{H}$ and continuation rise. In the former group, the connection is much less strong or simply does not hold: in Spanish, $\mathrm{L}+\mathrm{H}^{*}$ does not have to be followed by sustained pitch (in fact, with $\mathrm{L}+\mathrm{H}^{*}$ sustained pitch is observed in only $26 \%$ of the cases), and sustained pitch may appear with $\mathrm{L}^{*}+\mathrm{H}\left(9 \%\right.$ of the cases); in Catalan, $\mathrm{L}+\mathrm{H}^{*}$ is almost the only accent (except for $3 \%$ of $\mathrm{H}+\mathrm{L}^{*}$ ) and sustained pitch was not found.

Based on our data, we must conclude that from a cross-language perspective, nuclear accent type $\left(\mathrm{L}+\mathrm{H}^{*}\right.$ and $\left.\mathrm{L}^{*}+\mathrm{H}\right)$ and a sustained pitch or continuation rise configuration at the intonational boundary are independent choices and different languages combine these two properties of the nuclear contour in different ways.

\begin{tabular}{lllll}
\hline & \multicolumn{1}{c}{${\mathrm{L}+\mathrm{H}^{*}}$} & \multicolumn{1}{c}{$\mathrm{L}^{*}+\mathrm{H}$} & $\mathrm{H}+\mathrm{L}^{*}$ & $\mathrm{~L}^{*}$ \\
\hline Cat & ContRise & & & \\
Sp & ContRise/SusPitch & ContRise/SusPitch & & \\
\hline SEP & & ContRise & ContRise & \\
NEP & SusPitch & ContRise & ContRise & ContRise \\
It & SusPitch & ContRise & ContRise & ContRise \\
\hline
\end{tabular}

Table 3: Dominant nuclear contour types across languages.

Finally, we would like to comment on the phonology of the two types of boundary contours. Continuation rises involve a $\mathrm{H}$ boundary tone that may be preceded in some cases by a Low tone (e.g. in Catalan and Spanish, though not frequently) yielding a boundary of the (L)H type. Sustained pitch also involves a $\mathrm{H}$ boundary tone, and the high plateau may be analyzed as the result of a HL boundary where the $\mathrm{L}$ tone is responsible for the final sustained level (as proposed in Pierrehumbert 1980), or simply as the result of a !H boundary, 
assuming that downstep is an independent intonational feature (along the lines of work by Ladd 1983, 1996). The latter analysis would have the advantage of reserving the HL boundary type for complex boundaries that do involve a real rise-fall gesture (as in the case of yes-no questions in NEP, Vigário \& Frota 2003; or exhortative utterances in Catalan, Prieto, Aguilar, Mascaró, Torres \& Vanrell 2007).

\section{The phonetics of the $\mathrm{H}$ boundary tone}

This section examines the phonetics of the dominant boundary cue used by all the languages under study: the $\mathrm{H}$ boundary tone. A detailed analysis of the impact of different factors on the realization of the $\mathrm{H}$ boundary tone is provided, namely the type of nuclear accent (Section 5.1), the length of the phrase (Section 5.2), and the interdependence of the realization of $\mathrm{H}$ with the scaling of the first peak of the phrase (Section 5.3). The section concludes with a summary and discussion of the main findings.

\subsection{The impact of nuclear pitch accent choice on the scaling of the $H$} boundary

We have seen that the languages studied, with the exception of Catalan, may show different types of accents that frequently appear in nuclear position before the phrasing boundary. The realization of the $\mathrm{H}$ boundary tone (HBT) may thus be affected by the choice of nuclear pitch accent in these languages, along the lines suggested by Pierrehumbert (1980) for the upstep of $\mathrm{H} \%$ after a $\mathrm{H}$ tone but not after a $\mathrm{L}$ tone. A detailed examination of nuclear pitch accent choice as a factor constraining the scaling of HBT shows important and consistent effects across SEP, NEP, Italian and Spanish.

In SEP, HBT is higher after $\mathrm{L}^{*}+\mathrm{H}$ than after $\mathrm{H}+\mathrm{L}^{*}$ and this effect is consistent across speakers. Figure 3 (top panel) displays the data for speaker AG (who shows a significant difference in the scaling of HBT, $p<0.0001$ ). In NEP, HBT is also higher after rising accents than after falling/low accents $(\mathrm{p}<0.001)$. HBT is also higher after $\mathrm{H}+\mathrm{L}^{*}$ than $\mathrm{L}^{*}$, for both speakers (though it does not reach significance). This is illustrated by the data for speaker MI, who shows all four types of nuclear accent (Figure 3, bottom panel).

The data from Italian replicates the same basic finding that rising accents promote higher HBT than low/falling accents (for both speakers $\mathrm{p}<0.0001$ ), as shown in Figure 4.

In Spanish two types of rising accents were found, and HBT is consistently higher after $\mathrm{L}^{*}+\mathrm{H}$ than after $\mathrm{L}+\mathrm{H}^{*}$ across speakers, though the difference only reaches significance for speaker LM $(\mathrm{p}<0.05)$, who shows a more balanced distribution between accents (Figure 5). This result is not surprising, as $\mathrm{L}^{*}+\mathrm{H}$ is followed by a continuation rise in $92 \%$ of cases, whereas a continuation rise appears after $\mathrm{L}+\mathrm{H}^{*}$ in only $74 \%$ of the occurrences of this accent. 

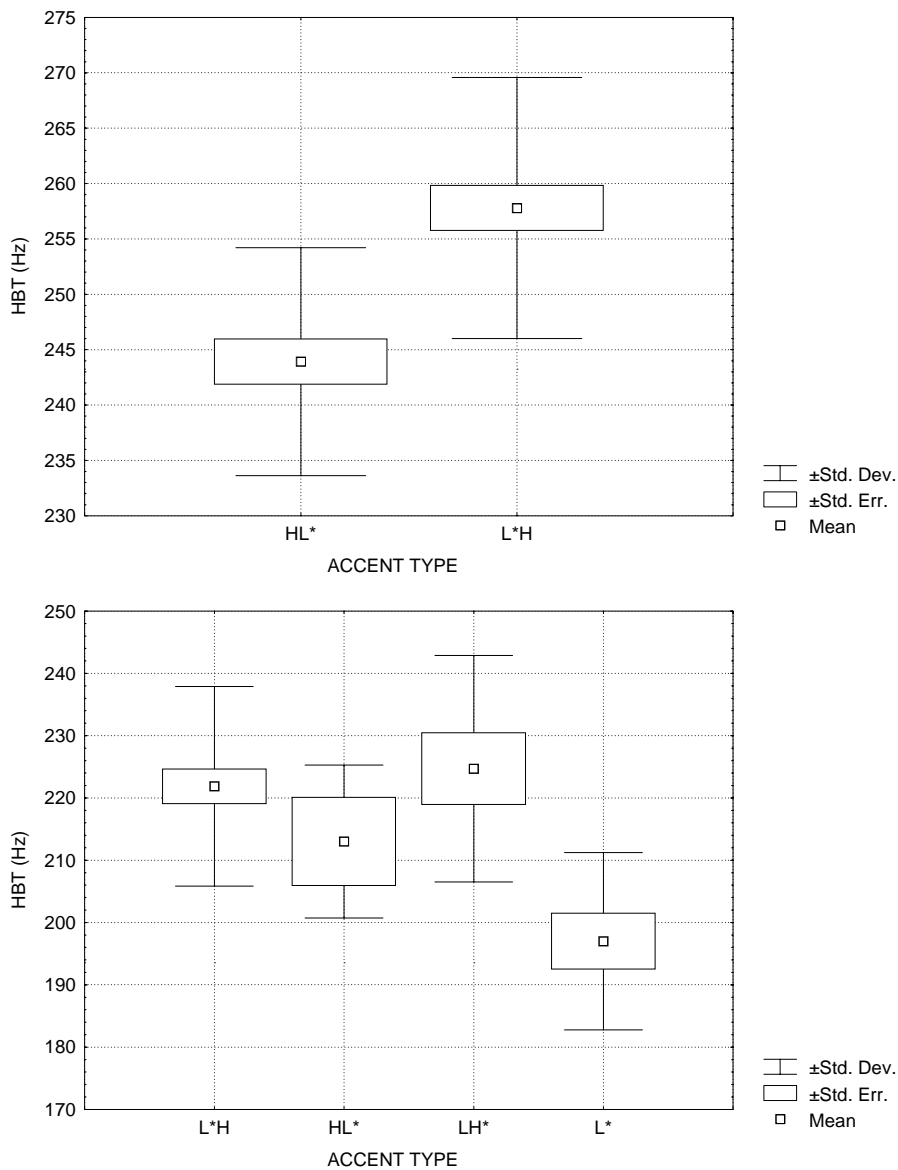

Figure 3: HBT scaling by type of nuclear accent. Top panel: speaker AG from SEP; bottom panel: speaker MI from NEP.

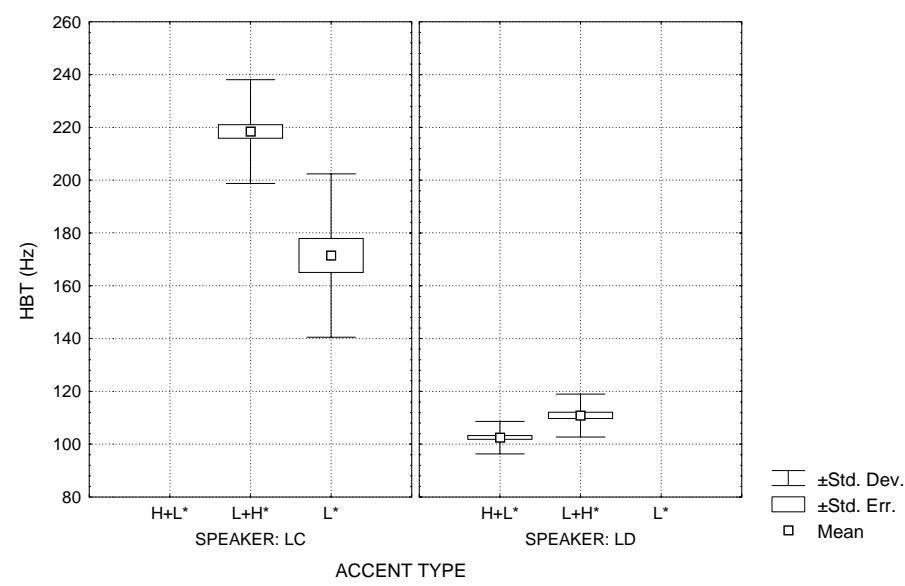

Figure 4: HBT scaling by type of nuclear accent for the two Italian speakers. 


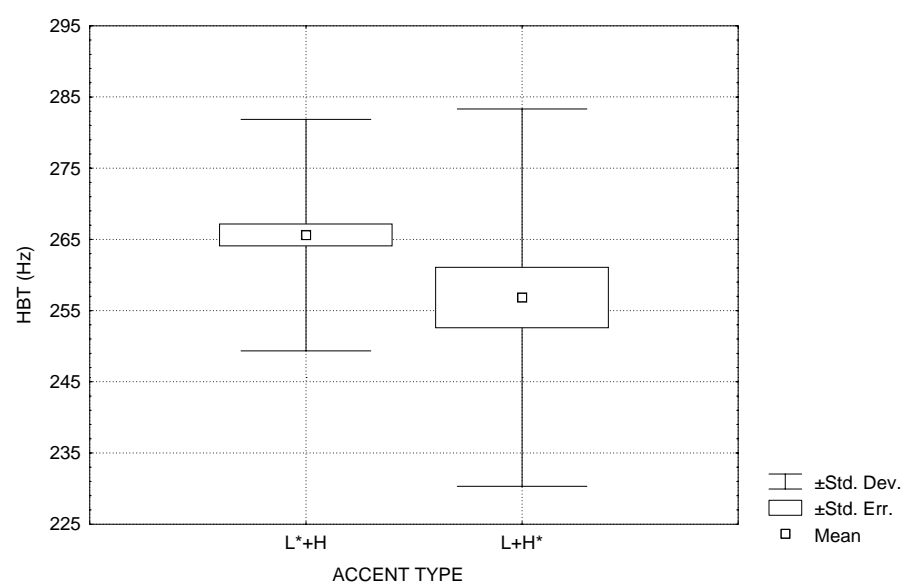

Figure 5: HBT scaling by type of nuclear accent for Spanish speaker LM.

We can conclude that nuclear pitch accent choice affects the scaling of HBT in a similar and consistent way in all the languages studied that use different pitch accents. The tendency is as follows: HBT is higher after $\mathrm{L}^{*}+\mathrm{H} / \mathrm{L}+\mathrm{H}^{*}$ than after $\mathrm{H}+\mathrm{L} * / \mathrm{L}^{*}$. Within rising accents, $\mathrm{L}^{*}+\mathrm{H}$ promotes higher HBT than $\mathrm{L}^{+} \mathrm{H}^{*}$ in Spanish. Within accents with a (final) Low tone, $\mathrm{H}+\mathrm{L}^{*}$ promotes higher HBT than $\mathrm{L}^{*}$ in NEP. Though only containing $\mathrm{L}^{+} \mathrm{H}^{*}$, the Catalan data is consistent with the cross-linguistic findings in that the $\mathrm{H}$ boundary tone shows high values in this language. This fact is revealed by a cross-language comparison of the ratios between HBT and the F0 values at the beginning of the utterance: in Catalan the ratios are very high (indeed it is the only language with ratios above 1.30), as one would expect from a rising accent plus HBT sequence where only continuation rises are found.

The findings just described can be interpreted as resulting from the upstep of HBT after an accentual H. This would account for the higher scaling of HBT after rising accents in general, relative to low/falling accents. Moreover, this implementation rule is independent of the downstep (phonological) feature we proposed to represent the sustained pitch configuration $(! \mathrm{H})$. Thus, a downstepped HBT would tend to be phonetically lower than a non-downstepped HBT, even if preceded by an accentual $\mathrm{H}^{4}$.

\subsection{The impact of phrase length on the scaling of HBT}

It has long been known that F0 tends to decline over the course of phrases (and utterances) in many languages, whether we consider the tendency shown by the topline or the baseline (e.g. Bruce \& Garding 1978; Liberman \& Pierrehumbert 1984; Pierrehumbert \& Beckman 1988; Ladd 1996; Prieto et al. 1996; Prieto 1998, among many others). However, languages seem to differ in the sources of global trends, as the scaling of any given tone may depend on a

\footnotetext{
${ }^{4}$ The reason why $\mathrm{H}+\mathrm{L}^{*}$ promotes higher HBT than $\mathrm{L}^{*}$ does is not totally clear at this point. However, we would like to suggest a functional interpretation in terms of contrast enhancement, along the lines suggested by Rialland (2001): after a fall, a higher target is required to facilitate both the perception of the low tone and the following high tone.
} 
variety of factors like phrasal length, phrasal position, temporal distance to preceding accent, F0 values of preceding accent, etc. For some languages, the global trend seems to be mainly due to localised changes in the contour (as proposed in Liberman-Pierrehumbert's model), whereas for others some amount of global pre-planning is required (see Rialland 2001; Gussenhoven 2004). In the former languages, phrasal length is not a crucial factor, unlike the F0 value of preceding accents (e.g. Prieto et al. 1996); in the latter languages, the length of the phrase is crucial and speakers tend to begin higher as the phrase gets longer (e.g. Rialland 2001). Within the same language, the factors affecting the scaling of different tones may also vary. For example, scaling of accentual peaks in Mexican Spanish is mainly predicted by the F0 value of the previous peak (Prieto et al. 1996), whereas scaling of $\mathrm{L}$ tones requires a combination of contextual factors, among them phrasal length (Prieto 1998).

In this section we examine the impact of the length of the phrase on the scaling of HBT. We have measured phrase length in number of syllables, and thus the distance between HBT and the beginning of the phrase (which is also the beginning of the utterance in our data) may vary from three to fifteen syllables. In our analysis of the length factor, we looked at the ratio between HBT and the F0 value at the beginning of the utterance (UttIni) across languages, for each speaker and by nuclear pitch accent type. We then checked whether the results found were mainly due to the impact of length on HBT scaling, UttIni scaling, or both.

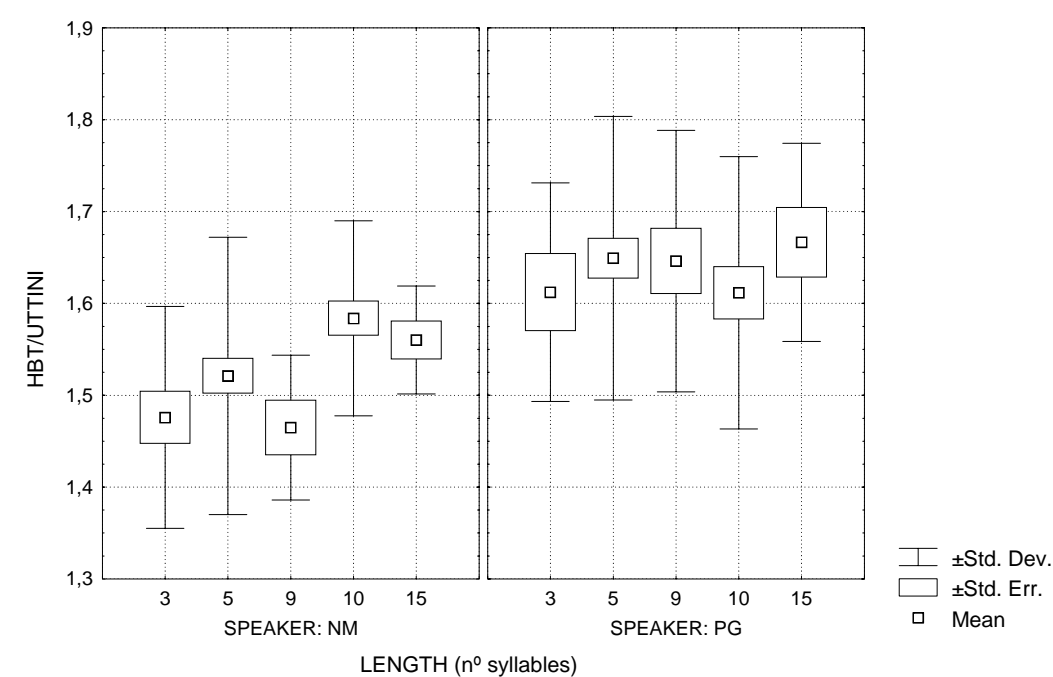

Figure 6: HBT/UttIni ratio as a function of phrase length in number of syllables, for both Catalan speakers.

In Catalan, although there is a slight tendency for the HBT/UttIni ratio to be higher in longer phrases, the effect is neither consistent nor significant, as shown in Figure $6(\mathrm{p}>0.01)$. 


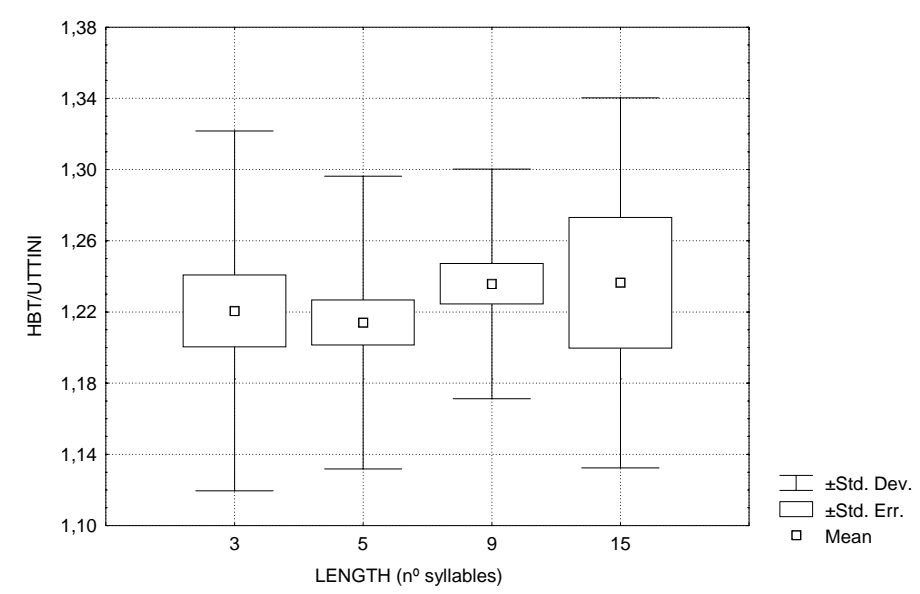

Figure 7: HBT/UttIni ratio as a function of phrase length in number of syllables, for the phrases produced with a $L^{*+H}$ nuclear accent by Spanish speaker LM.

Spanish is similar to Catalan in that no significant effect of phrase length was found for any of the speakers or accent types (ANOVA results for HBT/UttIni: speaker LM, $\mathrm{L}^{*+\mathrm{H}}$ and $\mathrm{L}+\mathrm{H}^{*} \mathrm{p}>0.05$; speaker MR, $\mathrm{L}^{*}+\mathrm{H}$ and $\mathrm{L}+\mathrm{H}^{*} \mathrm{p}>0.1$; ANOVA results for UttIni: $\mathrm{LM}, \mathrm{L}^{*}+\mathrm{H}$ and $\mathrm{L}+\mathrm{H}^{*} \mathrm{p}>0.1$; MR, $\mathrm{L}^{*}+\mathrm{H}$ and $\mathrm{L}+\mathrm{H}^{*} \mathrm{p}>0.1$ ). This is illustrated by the data for speaker $\mathrm{LM}$ showing the $\mathrm{L}^{*}+\mathrm{H}$ nuclear accent plotted in Figure 7 . In addition, there is no consistent tendency in Spanish to have higher or lower HBT/UttIni ratios, across speakers or accent types.

The European Portuguese data offer a very different picture. There is an overall tendency, consistent across speakers and accent types, to have lower HBT/UttIni ratios with increasing phrase length. This effect is clear in SEP (though not statistically significant) and in NEP, where it is significant for both speakers and the different accents, whether rising or falling (NEP; speaker MI $\mathrm{p}<0.01$ for $\mathrm{L}^{*}+\mathrm{H}$ and $\mathrm{p}<0.05$ for $\mathrm{L}+\mathrm{H}^{*}$; speaker MS $\mathrm{p}<0.0001$ for $\left.\mathrm{L}^{*}\right)$. The EP results are illustrated in Figure 8.

Our attempt to determine whether this clear effect of length was mainly due to an impact on the scaling of UttIni or on the scaling of HBT, or both, revealed an interesting finding. In SEP, no effect of length on HBT was found (ANOVA results: speaker $\mathrm{MC}, \mathrm{H}+\mathrm{L}^{*}$ accent $\mathrm{p}>0.1^{5}$; speaker $\mathrm{AG}, \mathrm{H}+\mathrm{L} *$ and $\mathrm{L}^{*}+\mathrm{H} \mathrm{p}>0.1$ ). However, phrase length had a strong and significant effect on UttIni: the beginning of the utterance becomes higher with increasing phrase length (ANOVA results: speaker $\mathrm{MC} \mathrm{p}<0.01$; speaker $\mathrm{AG} p<0.05$ ). This is shown in Figure 9, for speaker AG, which shows the reverse effect of that depicted in Figure 8 (left panel): UttIni is scaled higher as the phrase becomes longer (Figure 9), whereas the HBT/UttIni ratio diminishes with phrase length (Figure 8). Clearly, then, the effect of length on the HBT/UttIni ratio in SEP is crucially due to its effect on UttIni scaling, not HBT scaling.

\footnotetext{
${ }^{5}$ For this speaker there were not enough cases of $\mathrm{L}^{*}+\mathrm{H}$ across the different length conditions.
} 


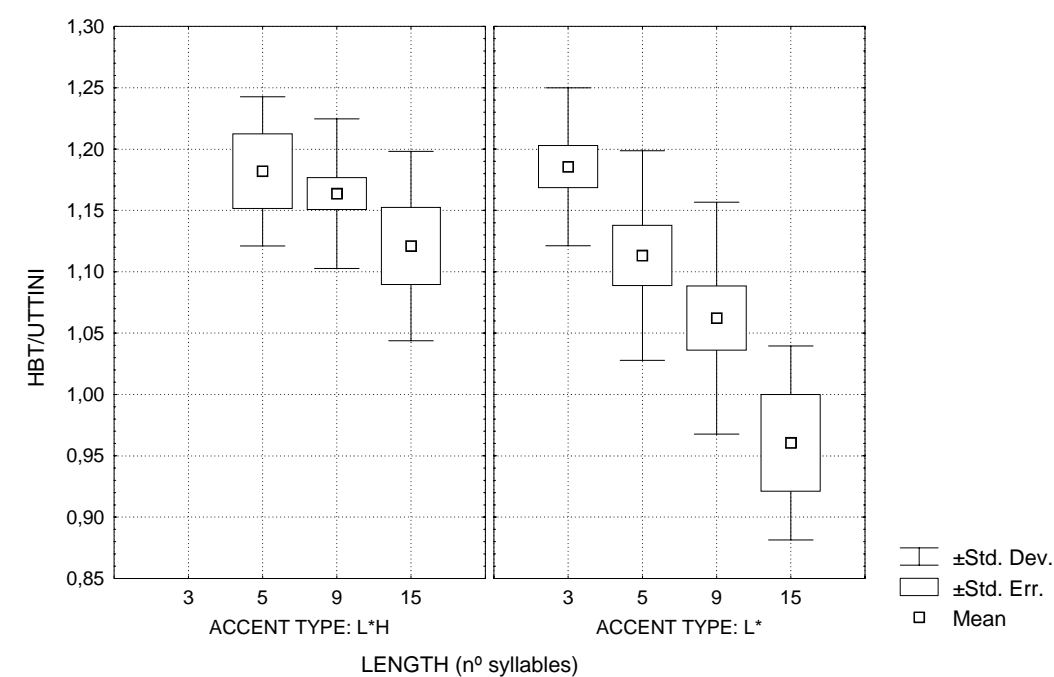

Figure 8: HBT/UttIni ratio as a function of phrase length in number of syllables. Left panel: phrases produced with a $L^{*+} H$ nuclear accent by SEP speaker AG. Right panel: phrases produced with a $L^{*}$ nuclear accent by NEP speaker MS.

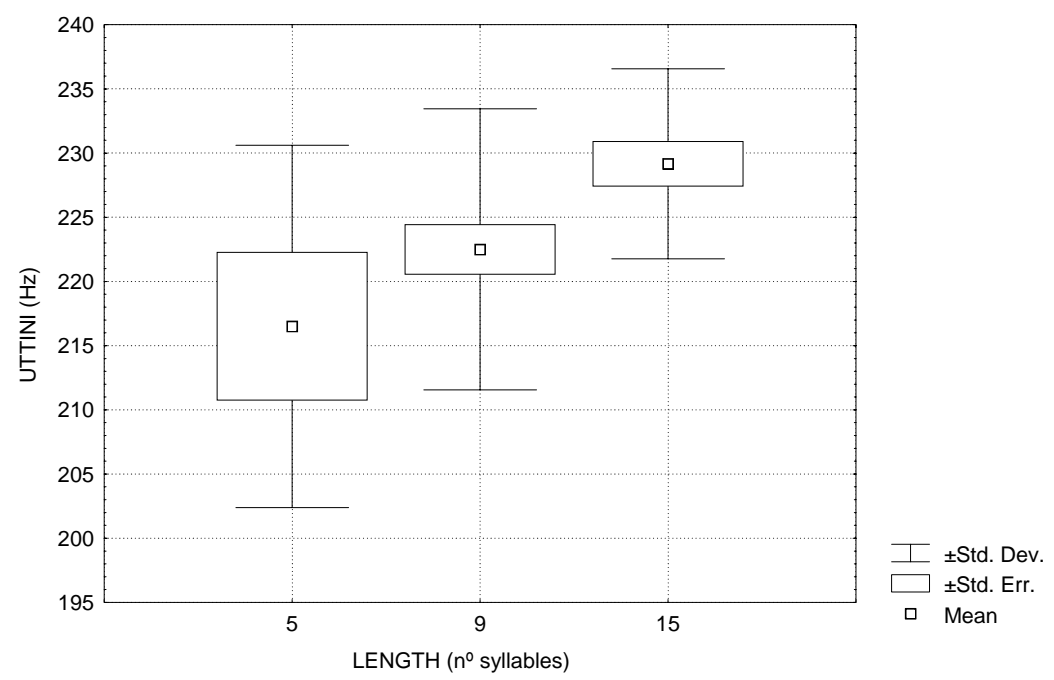

Figure 9: UttIni scaling as a function of phrase length for SEP speaker AG.

In NEP, by contrast, there is a consistent effect of phrase length on the scaling of HBT: HBT becomes lower as phrase length increases (ANOVA results: speaker MI $\mathrm{L}^{*}+\mathrm{H} \mathrm{p}<0.05$; speaker MS $\left.\mathrm{L}^{*} \mathrm{p}<0.0001\right)^{6}$. This is illustrated in Figure 10. As to the scaling of UttIni, there is only a slight tendency for UttIni to be higher with increasing length, but the effect is not significant (ANOVA results: speaker MI and speaker MS $\mathrm{p}>0.1$ ). Thus in NEP, unlike SEP, the significant effect of length on the HBT/UttIni ratio is crucially

\footnotetext{
${ }^{6}$ For the other nuclear accent types there was an insufficient number of cases in the different length conditions.
} 
due to an effect on HBT scaling. The HBT/UttIni ratio decreases with increasing length (Figure 8, right panel) because HBT is scaled lower as length increases (Figure 10). The effect is still reinforced by the slight tendency for UttIni to be scaled higher in longer phrases.

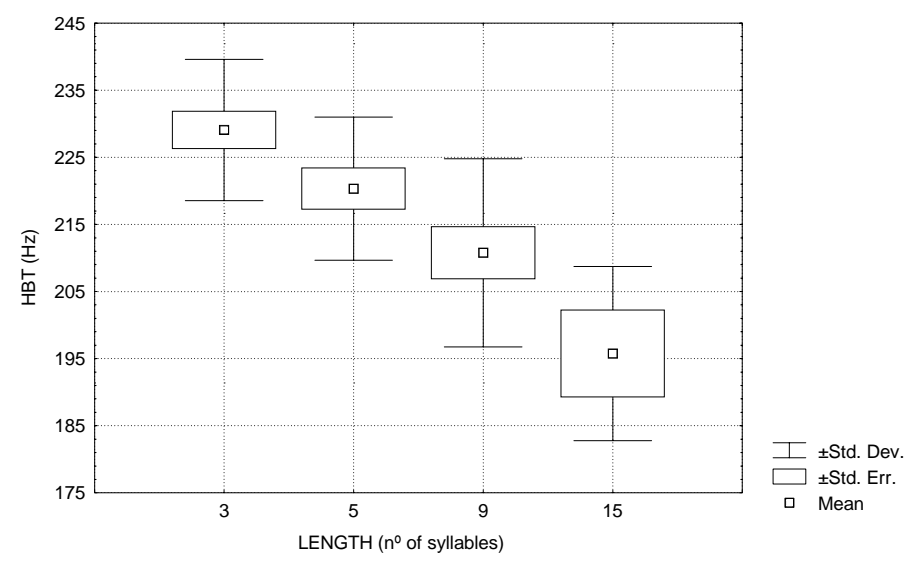

Figure 10: HBT scaling as a function of phrase length, for the phrases produced with a $L^{*}$ nuclear accent by NEP speaker MS.

In short, phrase length is a crucial factor in European Portuguese: lower HBT/UttIni ratios are obtained as the length of the phrase increases. However, in SEP length is crucial to the scaling of the beginning of the utterance, whereas in NEP length mainly affects the scaling of end of the phrase, that is, HBT.

Italian is similar to EP, as it also shows a tendency (which does not reach significance) for HBT/UttIni ratios to fall as the phrase becomes longer. This is consistent across speakers and nuclear accent types. Figure 11 provides an illustration of this pattern for speaker LD. In Italian, phrase length does not affect the scaling of UttIni, as shown in Figure 12 (ANOVA results: speaker LD and speaker LC $p>0.1$ ). In other words, the scaling of the beginning of the utterance is not sensitive to phrase length in this language. Thus, like in NEP, the tendency shown by the HBT/UttIni ratios seems to be due to an effect of length on the scaling of HBT (which reached significance for speaker LD, $\mathrm{p}<0.01)^{7}$.

Summing up, the impact of length on the scaling of HBT and UttIni reveals important differences across Romance languages. The languages observed seem to cluster in two main groups: (i) those showing an effect of phrase length, such as European Portuguese and Italian; (ii) those with no effect of length, such as Spanish and Catalan. Within the two groups, some further differences were found: (i) the first group shows lower ratios with increasing length; in SEP this is due to higher scaling of UttIni, while in Italian

\footnotetext{
${ }^{7}$ For a detailed analysis of the scaling of UttIni as well as the first peak in the RLD, see Prieto et al. (2006).
} 
length has no effect on UttIni but an effect on HBT, and in NEP length has a strong effect on HBT (which decreases with increasing length) combined with a tendency for higher scaling of UttIni; (ii) in the second group there is no clear effect of length, but a slight tendency to higher ratios in the longer phrases appears in Catalan, whereas in Spanish this is not consistent across speakers or nuclear accent types.

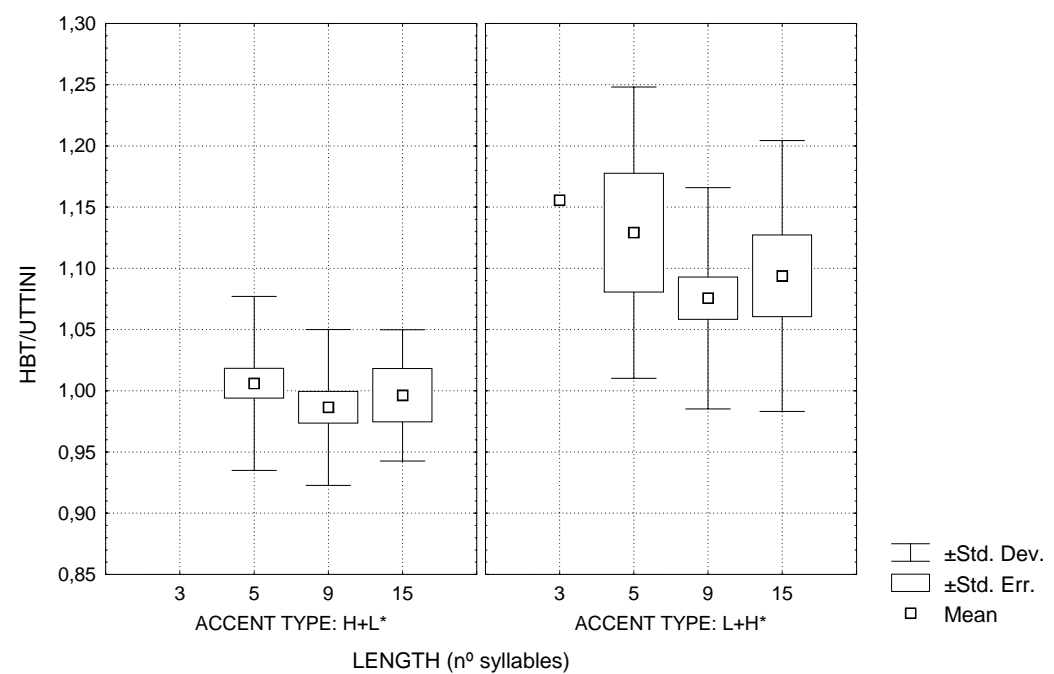

Figure 11: Ratio HBT/UttIni as a function of phrase length for the Italian speaker LD, by nuclear accent type.

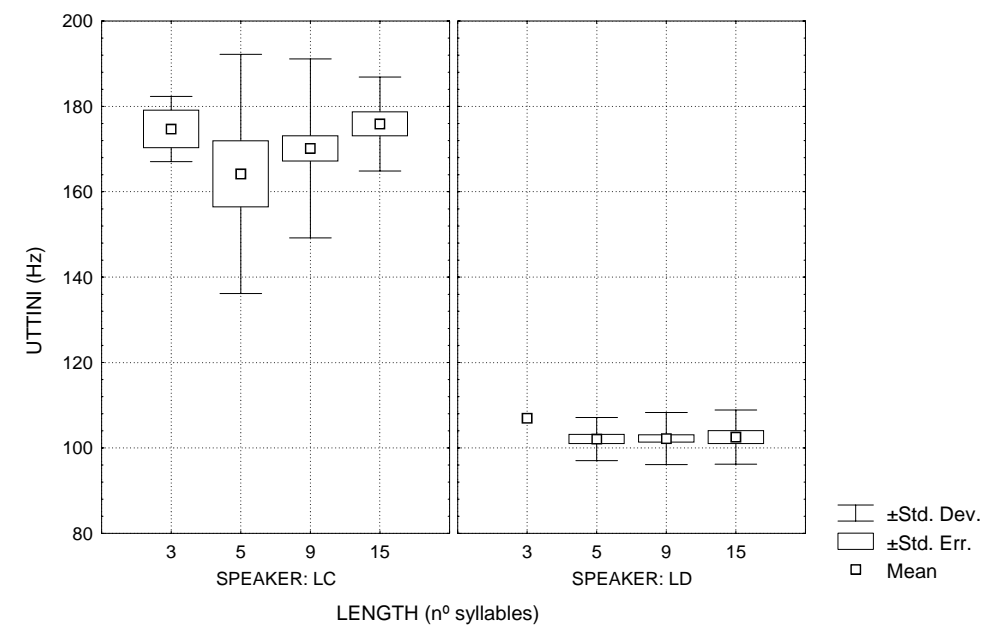

Figure 12: UttIni scaling as a function of phrase length for the two Italian speakers.

\subsection{Scaling correlation between the first peak and HBT}

We saw in Section 5.2 that Romance languages vary with respect to the importance of phrase length for the scaling of HBT (and for the beginning of 
the utterance). In the present section we examine the relation between the scaling of HBT and the scaling of the first peak (H1) of the phrase (which is also the first peak of the utterance in our data). It is known that, at least in some languages, the first peak sets the beginning F0 value from which the following peak value is computed, the process being locally iterated between adjacent peaks within the same phrase (e.g. Liberman \& Pierrehumbert 1984; van den Berg, Gussenhoven \& Rietveld 1992; Prieto et al. 1996). The question we set out to answer is whether the first peak has an influence on the scaling of the boundary peak in the languages observed. In the event that the iterated changes mentioned above do apply, we would expect to find a correlation between the scaling of the first peak and the scaling of HBT. If, on the other hand, HBT is scaled independently from the first peak (and the other peaks in the phrase), no correlation would be expected.

\begin{tabular}{lcccccccccc}
\hline Nuclear & \multicolumn{2}{c}{ Catalan } & \multicolumn{2}{c}{ Spanish } & \multicolumn{2}{c}{ SEP } & \multicolumn{2}{c}{ NEP } & \multicolumn{2}{c}{ Italian } \\
accents & PG & NM & LM & MR & MC & AG & MI & MS & LC & LD \\
\hline L+H* & $0.36^{*}$ & -0.14 & 0.13 & -0.25 & & & 0.36 & & 0.01 & 0.04 \\
$\mathrm{~L}^{*}+\mathrm{H}$ & & & $0.43^{*}$ & $0.44^{*}$ & & -0.13 & 0.16 & & & \\
$\mathrm{H}+\mathrm{L}^{*}$ & & & & & -0.07 & 0.17 & & -0.53 & & 0.06 \\
$\mathrm{~L}^{*}$ & & & & & & & 0.52 & 0.20 & 0.26 & \\
\hline
\end{tabular}

Table 4: Correlation coefficients for first peak in the phrase and HBT, by speaker and nuclear pitch accent type (significant results are indicated by *; for all significant cases found $p<0.001$ ).

Correlation results are given in Table $4^{8}$. In Catalan, a highly significant correlation was found for one of the speakers. Significant correlations were also found in Spanish, for both speakers, but only when the nuclear accent is of the $\mathrm{L}^{*}+\mathrm{H}$ type. Unlike Catalan or Spanish, no significant correlations were found in European Portuguese or Italian ( $p>0.05)$.

Again, the languages cluster in two groups: (i) those without significant correlations between H1 and HBT, that is, European Portuguese and Italian; and (ii) those showing significant correlations, that is, Catalan and Spanish. Notably, this is the same grouping that was found previously when analysing the phrase length effect on the scaling of the $\mathrm{H}$ boundary tone (Section 5.2).

\subsection{Summary and discussion}

The phonetics of the dominant boundary cue used in Romance languages - the H boundary tone-was analysed in Section 5. It was found that the choice of nuclear pitch accent is a major factor constraining the scaling of HBT in all the languages examined, and that this factor affects HBT height in a similar and consistent way across these languages: HBT is higher after rising accents $\left(\mathrm{L}^{*}+\mathrm{H} / \mathrm{L}+\mathrm{H}^{*}\right)$ than after falling or low accents $\left(\mathrm{H}+\mathrm{L}^{*} / \mathrm{L}^{*}\right)$. This finding was interpreted as resulting from the upstep of HBT after an accentual

\footnotetext{
${ }^{8}$ Blank cells in the table indicate that either the relevant accent type is not present in the speaker's data, or the number of cases with that accent type, a $\mathrm{H}$ boundary tone, and a first peak is too small (i.e. less than 5).
} 
$\mathrm{H}$, along the lines suggested by Pierrehumbert (1980) for upstep relations between $\mathrm{H}$ tones.

Unlike nuclear pitch accent choice, the impact of phrase length on the scaling of HBT, as seen by the ratio between HBT and the beginning of the phrase (UttIni), is not consistent across the languages, and both major and minor differences were found. The languages observed cluster in two groups. European Portuguese and Italian show a clear effect of phrase length. They show lower ratios with increasing length but in SEP this is due to higher scaling of UttIni, while in Italian there is no effect on UttIni, and in NEP there is a combination of both factors: a lower scaling of HTB and a tendency for higher scaling of UttIni. In contrast, Spanish and Catalan show no effect of phrase length (though a slight tendency to higher ratios in longer phrases appears in Catalan). The question arises as to whether the effect of length patent in the first group is a function of a whole phrase implementation effect or rather of a more local effect, such as the scaling of the previous accent. In the case of SEP, the available evidence points to a whole phrase effect, as it is the beginning of the phrase that is affected by the size of the phrase in a way similar to that described in Rialland (2001) for Dagara. In the case of NEP, evidence suggests a combined effect of local and global factors, as a main influence on HBT scaling was found together with a slight influence on UttIni. In Italian, only an influence on HBT scaling was found. How this local influence of phrase length on HBT should obtain in both NEP and Italian is a matter for future research. The best place to look seems to be the nuclear pitch accent, that is, the accent immediately preceding the boundary. We will thus explore this issue in the near future.

Like the phrase length factor, the influence of the first peak on the scaling of HBT is also not consistent across languages. The analysis of this factor divided the languages observed in the same two groups: European Portuguese and Italian on the one hand, with no significant correlation between HBT and the first peak of the phrase (H1), and Catalan and Spanish on the other hand, with significant correlations between $\mathrm{H1}$ and HBT. The interdependence between the scaling of HBT and the first peak in the latter group suggests that locally iterated changes in peak scaling within a phrase may apply in these languages. Indeed, in the Catalan data the number of accents in a phrase seems to affect the scaling of HBT, with HBT scaling higher in phrases with more accents. This may be taken as an indication that a local iterated computation between accents within a phrase (as shown by Prieto et al. 1996 for Mexican Spanish) and between the last accent and the boundary peak is an important factor to take into account in Catalan and Spanish. This is a topic to explore in further research.

Finally, the impact of the two last factors examined - phrase length and first peak scaling - on the height of the boundary peak clusters languages in exactly the same way: European Portuguese and Italian show an effect of length, but not an effect of the first peak; conversely, Catalan and Spanish show an effect of the first peak, but not a length effect. Another question to be 
addressed in future research within the Romance languages intonational phrasing project is whether this variation corresponds to different ways of implementing tone scaling across languages, as has been suggested in the literature (namely, via localized changes between adjacent peaks within a phrase as described in Liberman \& Pirrehumbert 1984, inter alia, or via global phrasal implementation as described in Rialland 2001, among others).

\section{Conclusion}

This paper described the phonetics and phonology of intonational boundaries in Catalan, two varieties of European Portuguese, Italian, and Spanish. A typology of the boundary cues used was put forward and their relative frequency was established. Due to the dominant use of the $\mathrm{H}$ boundary tone across these languages and its contribution to the two main types of boundary configurations found, continuation rise and sustained pitch, this paper has focused on the phonology and phonetics of the whole tonal gesture that signals phrasing boundaries in Romance.

It was shown that the phonology of intonational boundaries in Romance is characterized by two main properties: on one hand, these languages share the presence of the $\mathrm{H}$ boundary tone as a common feature, while on the other, nuclear pitch accent choice and the possible combinations of nuclear accent with the continuation rise/sustained pitch configurations divide these languages into two different groups. The phonetics of intonational boundaries offers a similar picture: nuclear pitch accent choice plays a major role on HBT scaling in all the languages, with HBT being upstepped after an accentual $\mathrm{H}$, whereas the other factors analysed split these languages into exactly the same two groups. Overall, the variation found is between the Catalan-Spanish group on the one hand, and the European Portuguese-Italian group on the other. Within the latter, the Northern variety of European Portuguese is consistently closer to Italian than the Standard variety.

It is hoped that the present findings will add to recent work on variation in intonation (inter alia, Grabe 2002; Chen 2003; Grice, D’Imperio, Savino \& Avesani 2005), and contribute to our understanding of the dimensions of variation in intonational phrasing in Romance languages.

\section{References}

Beckman, Mary \& Janet Pierrehumbert. 1986. "Intonational structure in English and Japanese". Phonology 3. 255-309.

-------- \& Gayle Ayers. 1994. "ToBI annotation conventions". http://ling.ohio-state.edu/ tobi/ame_tobi/.

---------, Manuel Díaz-Campos, Julia Tevis McGory \& Terrell A. Morgan. 2002. "Intonation across Spanish, in the Tones and Break Indices framework". Probus 14:1. 9-36.

Berg, Rob van den, Carlos Gussenhoven \& Toni Rietveld. 1992. "Downstep in Dutch: Implications for a model". Papers in Laboratory Phonology II: 
Gesture, Segment, Prosody ed. by Gerry Docherty \& D. Robert Ladd. 335-359. Cambridge: Cambridge University Press.

Bruce, Gösta \& Eva Garding. 1978. "A prosodic typology for Swedish dialects". Nordic Prosody ed. by Eva Garding, Gösta Bruce \& Robert Bannert. 219-228. Lund: Gleerup.

Chen, Aoju. 2003. "Language dependence in continuation intonation". Proceedings of the $15^{\text {th }}$ International Congress of Phonetic Sciences ed. by Maria-Josep Solé, Daniel Recasens \& Joaquín Romero. 1069-1072. Barcelona: Causal Productions.

D'Imperio, Mariapaola. 2000. The role of perception in defining tonal targets and their alignment. PhD diss., Ohio State University.

-------. 2001. "Focus and tonal structure in Neapolitan Italian". Speech Communication 33:4. 339-356.

--------. 2002. "Italian intonation: An overview and some questions". Probus $14: 1.37-69$.

--, Gorka Elordieta, Sónia Frota, Pilar Prieto \& Marina Vigário. 2005. "Intonational phrasing in Romance: The role of syntactic and prosodic structure". Prosodies ed. by Sónia Frota, Marina Vigário \& Maria João Freitas. 59-97. Berlin \& New York: Mouton de Gruyter.

Elordieta, Gorka, Sónia Frota, Pilar Prieto \& Marina Vigário. 2003. "Effects of constituent weight and syntactic branching on intonational phrasing in Ibero-Romance". Proceedings of the $15^{\text {th }}$ International Congress of Phonetic Sciences ed. by Maria-Josep Solé, Daniel Recasens \& Joaquín Romero. 487-490. Barcelona: Causal Productions.

--------, Sónia Frota \& Marina Vigário. 2005. "Subjects, objects and intonational phrasing in Spanish and Portuguese". Studia Linguistica 59:2/3. 110-143.

Estebas-Vilaplana, Eva. 2000. The use and realisation of accentual focus in Central Catalan. PhD diss., University College London.

Face, Timothy. 2002. Intonational Marking of Contrastive Focus in Madrid Spanish. Berlin: Lincom-Europa.

Frota, Sónia. 1997. "On the prosody and intonation of Focus in European Portuguese". Issues in the Phonology and Morphology of the Major Iberian Languages ed. by Fernando Martínez-Gil \& Alfonso MoralesFront. 359-392. Washington, D.C.: Georgetown University Press. --. 2000. Prosody and Focus in European Portuguese. New York: Garland.

---------. 2002a. "Nuclear falls and rises in European Portuguese: A phonological analysis of declarative and question intonation". Probus 14:1. 113-146.

---------. 2002b. "Tonal association and target alignment in European Portuguese nuclear falls". Laboratory Phonology 7 ed. by Carlos Gussenhoven \& Natasha Warner. 387-418. Berlin \& New York: Mouton de Gruyter. 
\& Marina Vigário. In press. "Intonational phrasing in two varieties of European Portuguese". Tones and Tunes, Volume I, Typological and Comparative Studies in Word and Sentence Prosody ed. by Tomas Riad \& Carlos Gussenhoven. Berlin \& New York: Mouton de Gruyter.

Grabe, Esther. 2002. "Variation adds to prosodic typology". Speech Prosody 2002 - Proceedings of the $1^{\text {st }}$ International Conference on Speech Prosody ed. by Bernard Bel \& Isabel Marlien. 127-132. Aix-enProvence: Laboratoire de Parole et Language, Université de Provence.

Grice, Martine, Mariapaola D'Imperio, Michelina Savino \& Cinzia Avesani. 2005. "Towards a strategy for labelling varieties of Italian". Prosodic Models and Transcription: Towards Prosodic Typology ed. by Sun-Ah Jun. 55-83. Oxford: Oxford University Press.

Grønnum, Nina \& Maria do Céu Viana. 1999. "Aspects of European Portuguese Intonation". Proceedings of the $14^{\text {th }}$ International Congress of Phonetic Sciences ed. by John Ohala, vol.3, 1997-2000. Berkeley: University of California.

Gussenhoven, Carlos. 2004. The Phonology of Tone and Intonation. Cambridge: Cambridge University Press.

Hualde, José Ignacio 2002. "Intonation in Spanish and the other IberoRomance languages: Overview and status quaestionis". Romance Phonology and Variation ed. by Caroline Wiltshire \& Joaquim Camps. 101-115. Amsterdam \& Philadelphia: John Benjamins.

Ladd, D. Robert. 1983. "Phonological features of intonational peaks". Language 59. 721-759.

---------. 1996. Intonational Phonology. Cambridge: Cambridge University Press.

Liberman, Mark \& Janet Pierrehumbert. 1984. "Intonational invariance under changes in pitch range and length". Language Sound Structure: Studies in Phonology Presented to Morris Halle by his Teacher and Students ed. by Mark Aronoff \& Richard Oehrle. 157-233. Cambridge, Mass.: The MIT Press.

McGory, Julia Tevis \& Manuel Díaz-Campos. 2002. "Declarative intonation patterns in multiple varieties of Spanish". Structure, Meaning, and Acquisition of Spanish. Papers from the $4^{\text {th }}$ Hispanic Linguistic Symposium ed. by James F. Lee, Kimberly L. Geeslin \& J. Clancy Clements. 73-92. Somerville: Cascadilla Press.

Nibert, Holly 2000. Phonetic and phonological evidence for intermediate phrasing in Spanish intonation. $\mathrm{PhD}$ diss., University of Illinois at Urbana-Champaign.

Pierrehumbert, Janet. 1980. Phonetics and phonology of English intonation. PhD diss., MIT.

-- \& Mary Beckman. 1988. Japanese Tone Structure. Cambridge, Mass.: MIT Press. 
Price, Patti, Mari Ostendorf, Stefanie Shattuck-Hufnagel \& Cynthia Fong. 1991. "The use of prosody in syntactic disambiguation". Journal of the Acoustical Society of America 90. 2956-2970.

Prieto, Pilar. 1995. "Aproximació als contorns entonatius del català central". Caplletra, Revista Internacional de Filologia 19. 161-186.

--------. 1998. "The scaling of the L values in Spanish downstepping contours". Journal of Phonetics 26. 261-282.

--------. 2005. "Syntactic and eurhythmic constraints on phrasing decisions in Catalan". Studia Linguistica 59:2/3. 194-222.

-------. 2007. "Phonological phrasing in Spanish". Optimality-Theoretic Advances in Spanish Phonology ed. by Fernando Martínez-Gil \& Sonia Colina. 39-61. Amsterdam \& Philadelphia: John Benjamins.

---------, Jan van Santen \& Julia Hirschberg. 1995. "Tonal alignment patterns in Spanish". Journal of Phonetics 23. 429-451.

---------, Chilin Shih \& Holly Nibert. 1996. "Pitch downtrend in Spanish". Journal of Phonetics 24. 445-473.

--------, Mariapaola D’Imperio, Gorka Elordieta, Sónia Frota \& Marina Vigário. 2006. "Evidence for soft preplanning in tonal production: Initial scaling in Romance". Proceedings of Speech Prosody 2006 ed. by Rüdiger Hoffmann \& Hansjörg Mixdorff. 803-806. Dresden: TUDPress Verlag der Wissenschaften.

----------, Lourdes Aguilar, Ignasi Mascaró, Francesc J. Torres \& Maria del Mar Vanrell. 2007. "CatToBI (Catalan Tones and Break Indices)". http://seneca.uab.es/atlesentonacio.

Rialland, Annie. 2001. "Anticipatory raising in downstep realization: Evidence for preplanning in tone production". Proceedings of the Symposium Cross-Linguistic Studies of Tonal Phenomena: Tonogenesis, Japanese Accentology, and Other Topics ed. by Shigeki Kaji. 301-321. Tokyo: Institute for Languages and Cultures of Asia and Africa/Tokyo University of Foreign Studies.

Sosa, Juan Manuel. 1999. La entonación del español: Su estructura fónica, variabilidad y dialectología. Madrid: Cátedra.

Vigário, Marina. 1998. Aspectos da Prosódia do Português Europeu: Estruturas com advérbio de exclusão e negação frásica. Braga: CEHUM.

-------- \& Sónia Frota. 2003. "The intonation of Standard and Northern European Portuguese". Journal of Portuguese Linguistics 2:2. 115-137. 

